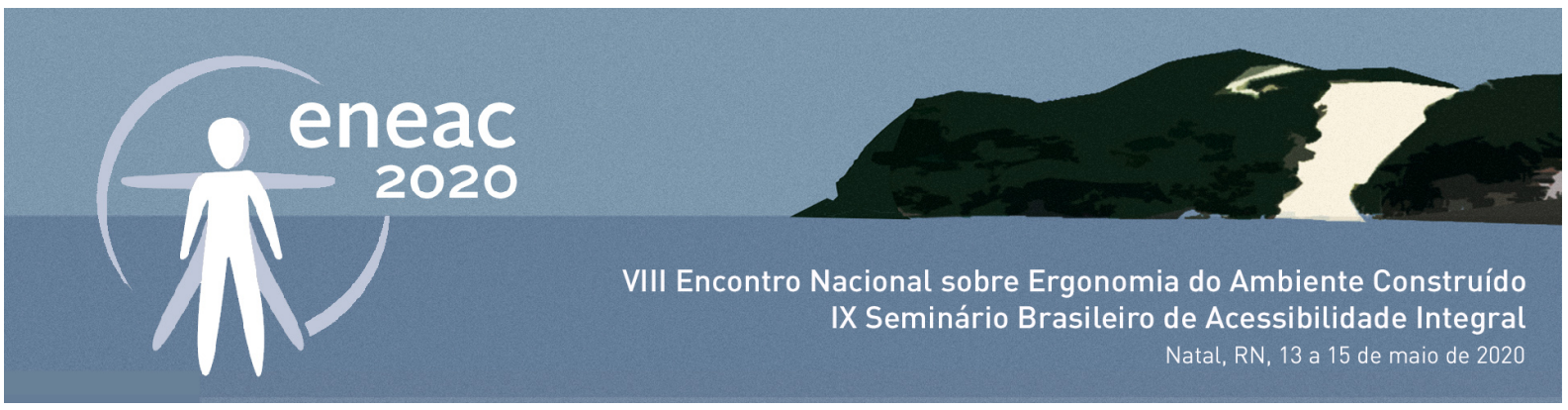

\title{
O ensino do método de Planejamento Espacial e sua relação com os princípios da Ergonomia do Ambiente Construído
}

\author{
The teaching of the Spatial Planning method and its relationship with \\ the principles of the Ergonomics of the Built Environment
}

GILBERTO RANGEL DE OLIVEIRA

UFRJ, D.Sc., e-mail: gilbertorangel@eba.ufrj.br

\begin{abstract}
RESUMO
Este artigo apresenta o método de Planejamento Espacial que é empregado como instrumento facilitador de ensino da disciplina Composição de Interior l e relaciona as etapas deste com os princípios da Ergonomia do Ambiente Construído (EAC). É apresentado ao leitor uma breve descrição da atividade de design de interiores e a importância do uso de metodologias projetuais - especialmente em se tratando da atividade prática do ensino; também são descritas as etapas do método dando-se ênfase às definições de território, usuário e conceito. São revisitados e reafirmados alguns conceitos de Ergonomia do Ambiente Construído, onde na sequência descreve-se os princípios da EAC e é demonstrado a relação destes com o método apresentado. Por fim, são traçadas algumas considerações e análise crítica sobre o uso do método aplicado no ensino de uma disciplina de projeto de interiores.
\end{abstract}

PALAVRAS-CHAVE: design interiores; método planejamento espacial; princípios ergonomia do ambiente construído

\section{ABSTRACT}

This article presents the Spatial Planning method that is used as a facilitator of teaching the discipline Composition Interior I and relates the stages of this with the principles of the Ergonomics of the Built Environment (EAC). The reader is presented with a brief description of the interior design activity and the importance of using design methodologies - especially when it comes to the practical activity of teaching; the steps of the method are also described, with emphasis on the definitions of territory, user and concept. Some concepts of Ergonomics of the Built Environment are revisited and reaffirmed, where the EAC principles are described next and their relationship with the presented method is demonstrated. Finally, some considerations and critical analysis are outlined on the use of the method applied in teaching an interior design discipline.

KEYWORDS: interior design; spatial planning method; principles environmental built ergonomics 


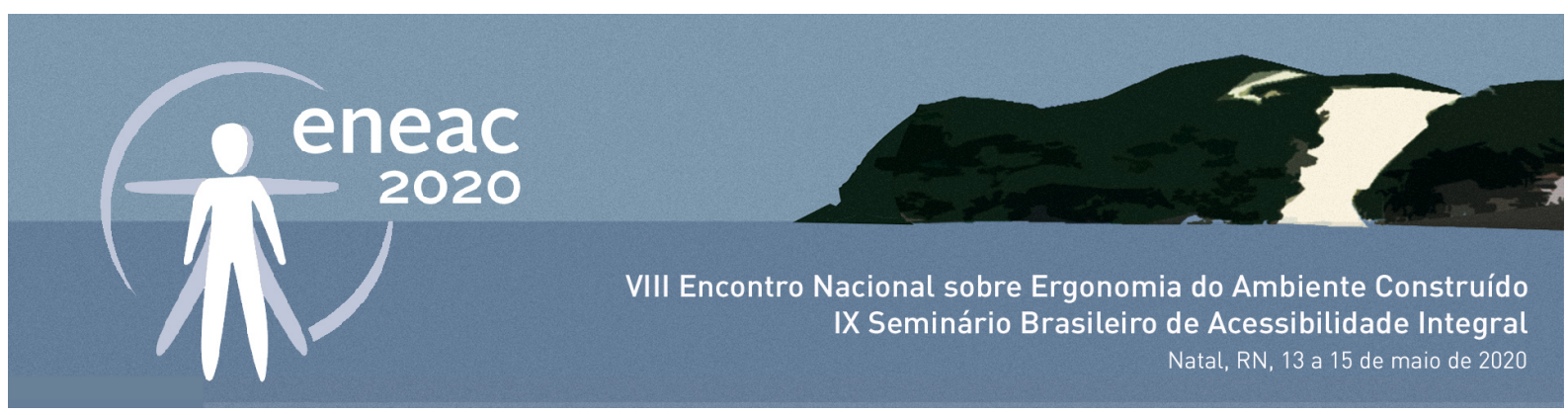

\section{INTRODUÇÃO}

O design de interiores ${ }^{1}$ é uma atividade que se dedica à criação de interfaces entre os usuários e as edificações que habitam e onde realizam suas atividades. "É uma atividade multidisciplinar que envolve a criação de ambientes internos que articulam o clima e a identidade por meio da manipulação dos volumes espaciais, da colocação de elementos específicos e mobiliário, além do tratamento das superfícies." (BROOKER e STONE, 2014, p. 12). Destaca-se que um número elevado de fatores deve ser considerado e manipulado pelo profissional de projeto no exercício projetual, o qual é previsto uma estratégia metodológica.

A palavra projeto neste apontamento corrobora com os escritos de SILVA $(1998$, p. 39) que diz, "projeto para os espaços arquitetônicos é uma proposta de solução para um problema específico de organização do entorno humano, através de uma determinada forma construtível, bem como a descrição desta forma e as prescrições para sua execução." Entende-se a importância de tratar do projeto enquanto processo, como entendê-lo praticá-lo e desenvolvê-lo. Desta forma, acredita-se que o projeto em si ainda não é uma solução finalizada do problema de projeto (arquitetônico ou de interiores), pois somente após a realização do trabalho proposto é que se irá satisfazer (ou não) realmente às necessidades dos usuários.

As necessidades dos usuários que se busca satisfazer na realização do projeto de design de interiores estão abrigadas sob dois aspectos principais: funcional e simbólico. Os aspectos funcionais devem contemplar a previsão de espaços necessários às atividades envolvidas e garantir que elas estejam distribuídas de modo apropriado, a fim de facilitar o uso particular. Sendo assim, estes aspectos atendem às demandas de layout, fluxo, organização espacial, conforto térmico, lumínico e acústico, ergonômico, de segurança, materiais para tratamento das superfícies, além de demandas específicas de equipamentos e acessórios previstos para atender o usuário. Os aspectos simbólicos concentramse em atender às necessidades culturais, a identidade do usuário, aspectos estéticos e ainda, as sensações possíveis de proporcionar ao usuário.

A história da formação de projetistas (em especial arquitetos, designers e designers de interiores) mostra que progressivamente o local de trabalho foi trocado pelo ateliê de projeto das universidades. Lawson (2011) explica que a formação dos profissionais de projeto tem algumas características muito comuns que transcendem os países e os campos de atividade.

\footnotetext{
Tipicamente, as escolas usam o ateliê físico e conceitual como principal mecanismo de ensino. Em termos conceituais, o estúdio é um processo de aprender fazendo, no qual os alunos recebem uma série de problemas de projeto para resolver. Assim aprendem a projetar principalmente na prática, em vez de empregar estudos ou análises. (LAWSON 2011, p:19)
}

Contudo, o autor faz sérias críticas quanto ao afastamento do aluno em relacionar dados e realizar reflexões, correlacionar fatos, avaliar todo o processo e aproveitar a tecnologia existente. "Parece quase impossível aprender a projetar sem pôr a mão na massa. Um dos pontos fracos do estúdio tradicional é que os alunos, por dar muita atenção ao produto final do trabalho, deixam de refletir

\footnotetext{
1 O termo design de interiores é utilizado como nomenclatura oficial da atividade conforme Lei de Regulamentação da Profissão № 13.369/16 sancionada em 13/12/2016. Também se utiliza o termo projeto de interiores (utilizado por alguns autores) para designar a mesma atividade, sem prejuízo de suas características próprias.
} 


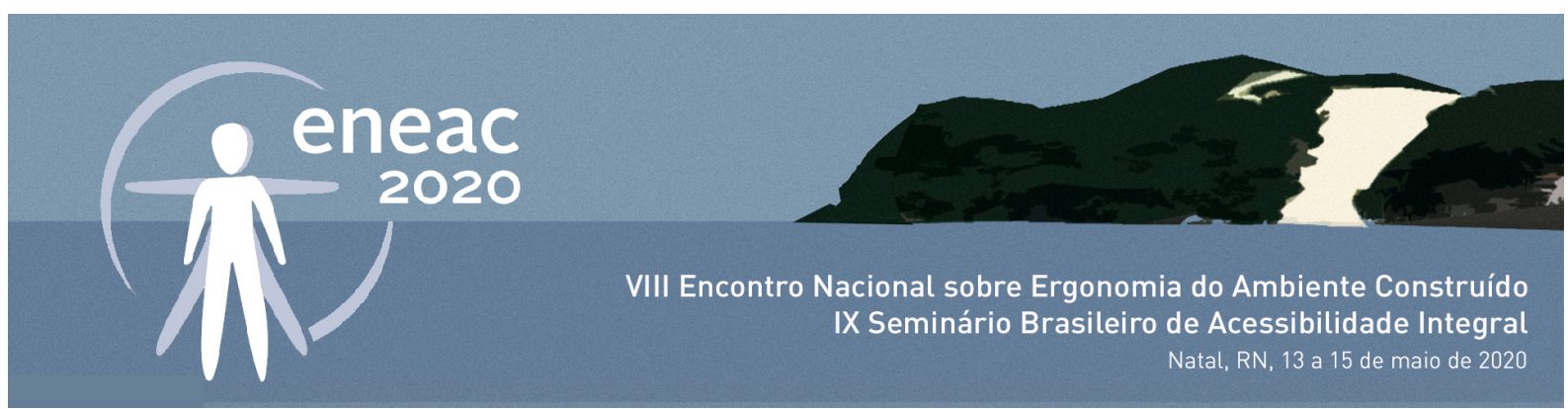

suficientemente sobre o processo." Nesse sentido o autor conclui que, "é fácil o estúdio didático transformar-se num lugar fantasioso e distante das necessidades do mundo real onde os alunos trabalharão quando se formar [...] no processo isso tende a distorcer não só o equilíbrio de habilidades como também o conjunto de valores que os alunos adquirem." Ibid, p. 19.

A aplicação de metodologias de projeto no âmbito do ensino acadêmico é tema amplo com diversas discussões e posições controversas. Os desafios aqui expostos tornam-se ainda mais significativos quando se faz necessário o planejamento didático para exposição de todas as necessidades projetuais do usuário, as complexidades implícitas do problema de projeto e a inexperiência natural de alunos ávidos por conhecimento. Diante deste cenário, é providencial utilizar-se de instrumentos metodológicos que auxiliem o aluno no desenvolvimento do seu trabalho, constituído de algum processo reflexivo. No percurso da disciplina obrigatória $\angle O M I T I D O$ REVISÃO CEGA>, aplica-se um método analítico divididos por seções específicas relativo à fase inicial do projeto. O método de Planejamento Espacial utiliza-se de um perfil de usuário fictício único, proposto pelo docente para todo grupo de alunos e de uma edificação residencial de até $100 \mathrm{~m}^{2}$, com planta arquitetônica definida e adequada aos padrões legais do Código de Obras da cidade do Rio de Janeiro.

Neste artigo apresenta-se o método de Planejamento Espacial, utilizado como ferramenta didática pedagógica no ensino de execução de projeto de interiores e a relação desta metodologia com os princípios básicos da ergonomia do ambiente construído². Ao final serão delineadas algumas considerações sobre a aplicação do método no ambiente acadêmico.

\section{MÉTODO DE PLANEJAMENTO ESPACIAL}

Método é o caminho para se atingir um determinado objetivo, podendo ser composto de várias técnicas (meios) que facilitem o processo. Pazmino (2015) explica que "o método envolve instrumentos de planejamento, coleta, análise e síntese, caracterização dos instrumentos, materiais com o qual o designer trabalha." Os métodos de projeto não são inimigos da criatividade, imaginação ou intuição - ao contrário, eles conduzem a soluções inovadoras, sendo que alguns métodos são técnicas específicas para auxiliar o pensamento criativo. Contudo, a autora lembra que "o método pressupõe sistemática de trabalho, organização, e rigor no desenvolvimento do processo, podendo representar os passos aplicados nos processos de design, ou seja, o ato concreto da realização e o caminho." (PAZMINO, 2015, p. 11).

Coelho (2011) lembra que em alguns casos o uso da palavra metodologia no meio acadêmico costuma ter diferentes denominações, com ênfase ao "campo teórico de determinada área ou concentrando-se em grandes áreas, como é o caso de disciplinas que trabalham conteúdos a partir das ciências biológicas, sociais, humanas ou físicas". Os estudos realizados nessas pesquisas costumam contemplar tanto a teoria metodológica em si, quanto sua aplicação em objetos

\footnotetext{
2 Estes princípios foram organizados a partir da leitura, análise e estudos sobre as publicações de alguns autores que tem a Ergonomia do Ambiente Construído, como objeto de estudo constante ao longo de anos. Este artigo não tem a intenção de ser conclusivo sobre o assunto. Apenas relacioná-lo com a aplicação do método de Planejamento Espacial. Os mesmos foram apresentados pelo autor na defesa da Tese de Doutorado em Design, intitulado Método de Projeto de Interiores, defendida em abril de 2016 na Pontifícia Universidade Católica (PUC-Rio) e mais tarde publicada pelo autor na Revista Ergodesign \& $\mathrm{HCl}$ em 2018.
} 


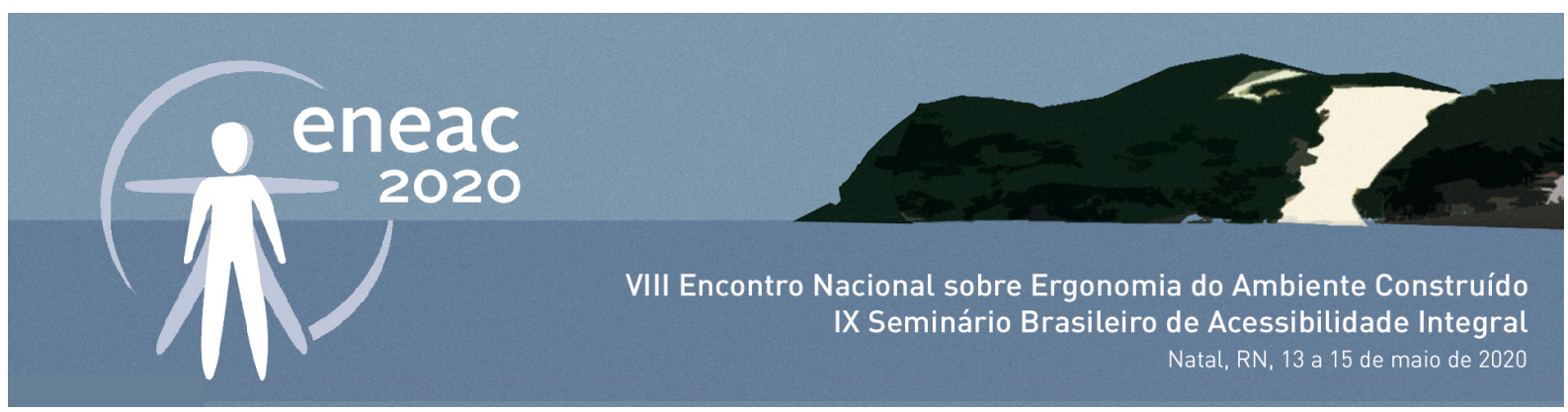

específicos (metodologia aplicada). Neste caso, o estudo de disciplinas com esse entendimento privilegia a chamada metodologia científica "embora trabalhem, por vezes, com procedimentos metodológicos particulares a um campo delimitado". Nesse sentido, corrobora-se com o entendimento do autor sobre metodologia aplicada no campo do design, o qual tem sido empregado na atividade de design de interiores.

É o caso, por exemplo, do curso de Design, em que o chamado método projetual é ensinado. Justifica-se esse tipo de tratamento da disciplina sobre métodos no ensino do design em FUNÇÃO de peculiaridades da profissão, que exige conhecimentos sólidos de PROJETO (COELHO, 2011, p: 252 e 253).

No sentido de reforçar a importância do uso de métodos de projeto no desenvolvimento de espaços planejados, defendidos nesta pesquisa, traz-se a constatação de Karlen (2010, p. 16), onde o autor afirma que do ponto de vista prático e profissional que o designer precisa de um processo eficiente e confiável ao qual deve recorrer sempre que se deparar com um projeto de design de interiores.

"Reunir alguns fatos básicos e ficar olhando para uma planta baixa em branco até que a inspiração surja é uma abordagem totalmente inviável".

Considerando-se as assertivas acima expostas e com o objetivo de compreender a fundo a relação do usuário e o ambiente construído, aplica-se o método de Planejamento Espacial. Esta ferramenta trata de investigar os problemas de projeto durante a etapa do processo de planejamento do ambiente que se inicia assim que os problemas são apresentados ao aluno e termina quando o projeto gráfico (como elemento de linguagem representativa) é elaborado. Esta etapa pertence a fase inicial do projeto, que conforme consenso entre os autores de metodologia projetual no design, compreende: planejamento, análise, síntese e criatividade ${ }^{3}$.

O termo método de Planejamento Espacial tem inspiração no método "Metodologia de Planejamento", (Karlen, 2010 p. 4-38), que de forma clara e concisa, "dedica mais atenção às partes preliminares do processo, ou seja, àquelas associadas ao planejamento e ao projeto." Karlen, que pertence ao Programa de Mestrado em Belas Artes - Arquitetura de Interiores do Moore College of Art \& Design, Filadélfia - EUA, trata a etapa do processo de planejamento do ambiente nas fases preliminares, que se iniciam assim que "os problemas de projeto são apresentados ao projetista (com ou sem um programa de necessidades) e que termina quando o planejamento físico começa geralmente, com organogramas ou plantas baixas esquemáticas". A metodologia proposta por Karlen (2010) é composta das seguintes fases: (1) O processo de síntese; (2) O programa de necessidades; (3) A matriz de critérios; (4) Esboços de planta baixa; (5) O preenchimento da matriz de critérios; (6) Os diagramas de relações. A "Metodologia de Planejamento", encerra-se quando se inicia o

planejamento físico e o desenvolvimento de plantas baixas, com todas as implicações espaciais e projetuais diversas - e a fase do planejamento de espaços e plantas baixas esquemáticas.

O método de Planejamento Espacial apresentado aqui, nasce a partir de um problema proposto e termina com a execução gráfica do projeto de interiores. É composta de uma estrutura divida em quatro fases: 1) levantamento de dados, análise e diagnoses sobre o território e o usuário; 2)

\footnotetext{
3 OLIVEIRA, Gilberto Rangel. MÉTODOS DE PROJETO DE INTERIORES NO BRASIL. Revista ErgodesignHCI, [S.I.], v. 6, n. Especial, p. 29 - 43, july 2018. ISSN 2317-8876. Disponível em: <http://periodicos.puc-rio.br/index.php/revistaergodesignhci/article/view/526>. Acesso em: 15 jan. 2020.
} 


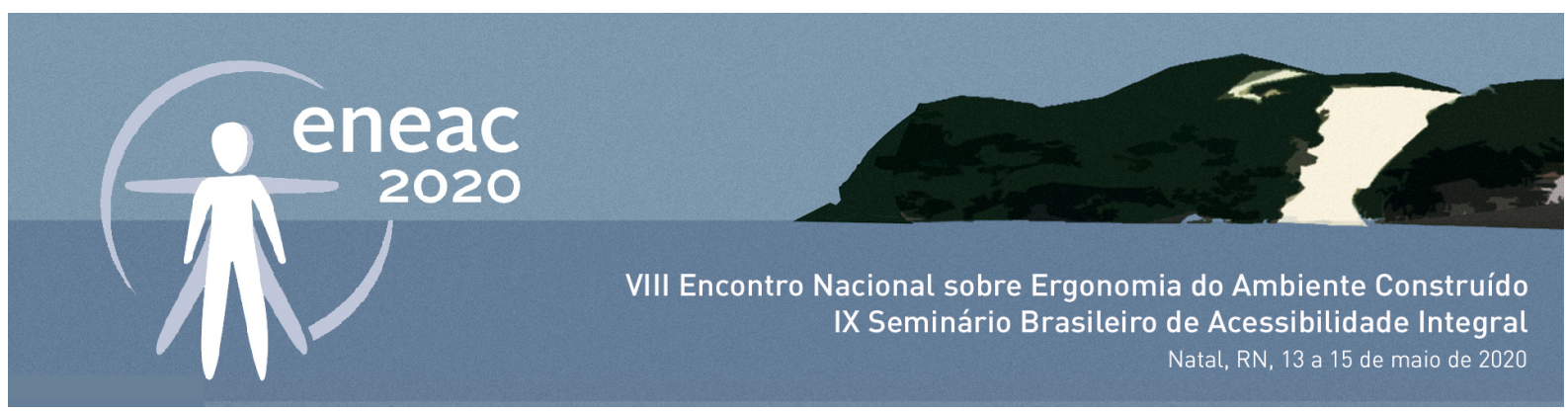

elaboração de quadro resumo e quadro de funções, atividades, equipamentos e acessórios; 3 ) elaboração do conceito e partido do projeto de interiores; 4) execução de esboços e do projeto gráfico final contemplando o conceito e o partido propostos.

A fase 1 e 2, trata-se de uma etapa analítica e reflexiva onde o foco está centrado no território e no usuário; o processo ocorre de forma verbalizada e escrita, que são organizados através de planilhas e tabelas. A fase 3 tem o objetivo de gerar um conceito e um partido de projeto identificado com o perfil do usuário proposto. Em seguida, parte-se para elaboração gráfica do projeto com a prática de esboços, estudos prévios de layout, até chegar à representação gráfica final, conforme normas da ABNT - fase final do processo (fase 4).

A representação gráfica do projeto é elaborada manualmente, com instrumentos de desenho e acessórios complementares de colorir. Entende-se que a representação gráfica realizada manualmente (especialmente para os alunos iniciantes, como é o caso) através de esboços, croquis e desenho final, contribui significativamente para o desenvolvimento mental de habilidades. Este é um assunto controverso e não é objetivo deste artigo, contudo, corrobora-se com o pensamento de Lawson (2011), quando cita Donald Schön (1983) que explica "os desenhos fazem parte do processo mental de pensar projeto [...] o projetista realiza o ato de desenhar não para se comunicar com os outros, mas para seguir uma linha de pensamento. Conforme se desenvolve, a imagem do desenho permite ao projetista "ver" novas possibilidades ou problemas". (LAWSON, apud SCHÖN, 2011 p. 246)

Esta prática metodológica de ensino projetual vem sendo aplicada, com algumas variações, como processo educativo no ensino de projeto de interiores, praticada no curso Composição de Interior da Escola de Belas Artes, da Universidade Federal do Rio de Janeiro - UFRJ, por professores das disciplinas de projeto já algum tempo ${ }^{4}$. Diante do fato que há muito pouco escrito sobre os métodos de planejamento espacial, principalmente do ponto de vista acadêmico, pretende-se antes de tudo, realizar um registro histórico do assunto, explicitar a aplicação do método, demonstrar a relação deste com os princípios básicos da ergonomia do ambiente construído e traçar algumas considerações sobre sua aplicação. Para melhor compreensão do método Planejamento Espacial, será explicitado em seguida algumas considerações sobre os termos território, usuário e conceito.

\section{O Território}

Moraes (2005, p. 78) relatou alguns esclarecimentos sobre qual território ${ }^{5}$ tratamos. Inicialmente a autora cita Santos (1993) que explica território "é mais que um conjunto de objetos mediante os

\footnotetext{
${ }^{4}$ Nota do autor: As Profas. Nora Geoffroy e Ecilia Cirne, do curso Composição de Interior da Escola de Belas Artes, da Universidade Federal do Rio de Janeiro - UFRJ, foram as idealizadoras da técnica de geração de dados, analises e diagnoses - sobre o território e o usuário, elaborando seu conteúdo, aplicando e desenvolvendo a técnica junto aos alunos das disciplinas de composição de interiores, testando e a aprimorando sua prática ao longo dos anos.

5 Nota do autor: Neste artigo o termo território, afasta-se do natural entendimento que simplesmente refere-se a uma área delimitada sob a posse de um animal, de uma pessoa (ou grupo de pessoas), de uma organização ou de uma instituição. E afasta-se mais ainda, quando o termo é empregado na política (referente ao Estado Nação, por exemplo), na biologia (área de vivência de uma espécie animal) e na psicologia (ações de animais ou indivíduos para a defesa de um espaço, por exemplo).
} 


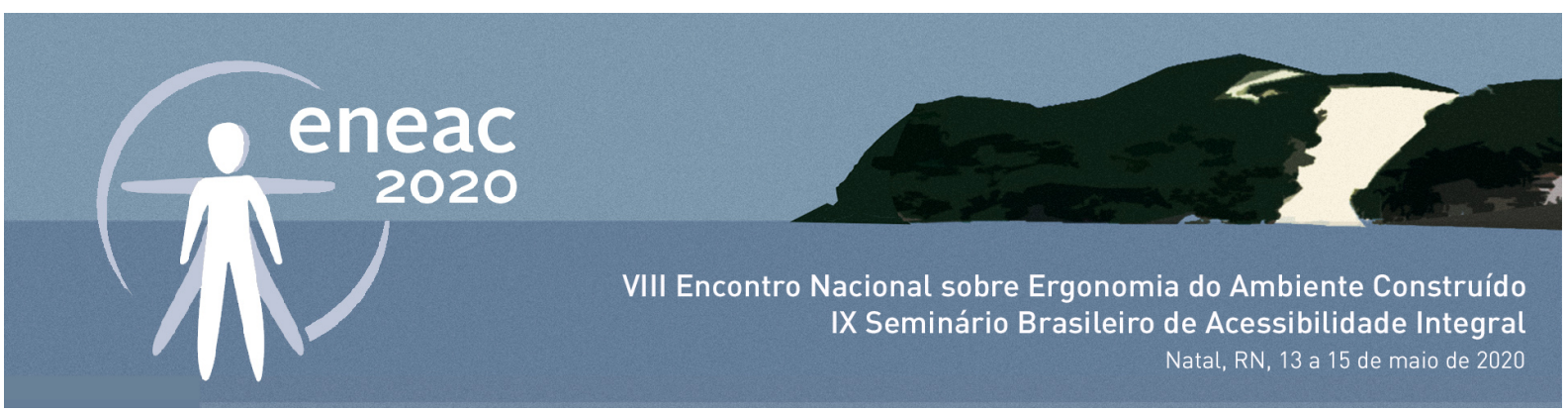

quais trabalhamos circulamos, moramos, mas também um dado simbólico". Mais a adiante a autora lembra as ideias de Siergfried Lenz, que nos diz que "território é o lugar onde temos as nossas raízes, onde possuímos nossa casa, falamos nossa linguagem, pulsamos nossos sentimentos mesmo quando ficamos em silêncio. É o lugar onde sempre somos reconhecidos".

Por fim, a autora chama a atenção para Fischer (1989) que estabelece uma distinção entre território e espaço pessoal: "espaço pessoal é uma zona móvel e invisível que circunda as pessoas; território é visível e estável." (MORAES apud SANTOS, FISCHER, 2005, p. 78)

Seguindo a mesma linha de raciocínio vale destacar o sentido amplo da palavra lugar - que traduz satisfatoriamente de qual território abordado neste estudo. Risério $(2019$, p. 26), aponta para as considerações do teórico norueguês Christian Norberg-Schulz, no livro Uma nova agenda para a arquitetura, através do texto $O$ fenômeno do lugar, onde o autor escolhe a palavra lugar como uma expressão concreta para falar do ambiente (natural ou construído).

\begin{abstract}
Lugar é algo mais do que uma localização abstrata. É "uma totalidade constituída de coisas concretas que possuem substância material, forma, textura e cor". E é uma realidade que deve ser pensada em termos ecológicos e antropológicos, desde que mesmo os lugares destinados a abrigar as funções mais básicas da existência, como comer e dormir, variam segundo climas e culturas. É assim que nosso filósofo parte para analisar a "estrutura do lugar", que pode ser uma cidade, um bairro, uma rua, uma casa. (RISÉRIO, 2019 apud NESBITT, 2010).
\end{abstract}

Fig. 1 TERRITÓRIO - Método de Planejamento Espacial.

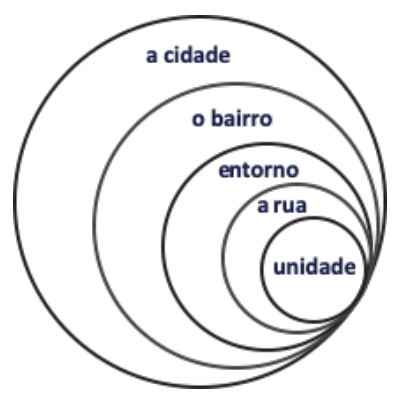

Fonte: o autor

A investigação do território na aplicação do método de Planejamento Espacial consiste em compreender a interação do usuário com a cidade, o bairro, o entorno imediato, a rua, o edifício e a unidade residencial (Fig. 01). A partir da técnica de observação (in loco) e análise de documentos específicos, levanta-se dados sobre: localização geográfica; características físicas e climáticas; aspectos históricos; patrimônio cultural (bens de natureza material e imaterial, paisagem cultural); aspectos físicos, econômicos, socioculturais; sistema viário, tráfego e meios de transporte; fluxos de pedestres; uso e ocupação do solo - institucional, comercial, residencial, misto; cobertura vegetal; microclima; passeios; ruídos; cobertura vegetal e iluminação pública. No edifício verifica-se aspectos tais como: acessibilidade, áreas comuns, formas de coleta de resíduos, número de pavimentos e unidades habitacionais circulações verticais e horizontais, orientação solar, materiais utilizados, envasaduras, entre outros. Por fim, na unidade habitacional, a partir da planta arquitetônica, faz-se uma análise minuciosa, sobre área construída, funções dos compartimentos, dimensões, pé-direito, vãos de ventilação e iluminação, paisagem, vãos de acesso (tipologia, material, dimensão); invasão de privacidade interna e externa - olfativa, auditiva e visual. 


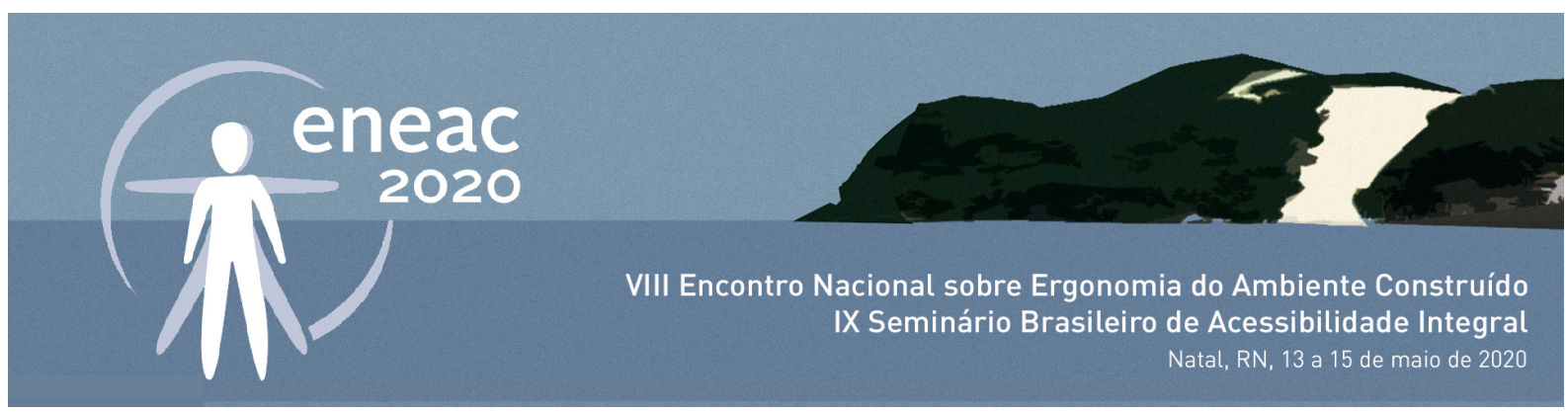

\section{O Usuário}

Todo mundo é usuário, se considerarmos a relação do homem com o território e sua interação. Moraes (2011, p. 92-93) explica que o usuário não é um monólito. "Aquele que denominamos usuário é determinado por nossas perspectivas. Existe o usuário como uma abstração. Existe o usuário como sujeito de testes. Existe o usuário como um ideal que se deve considerar, e cujos limites e capacidades devemos incorporar ao projeto".

Na disciplina de Composição de Interiores I, por razões pedagógicas, faz-se uso de um usuário ficcional. O professor da matéria desenvolve uma história fictícia onde propõe uma persona com características particulares de vida pessoal e profissional, valores, hábitos, rotinas e suas principais atividades. Estes dados são analisados em separado e mais tarde faz-se os cruzamentos necessários com os dados obtidos a partir da análise do território estudado considerando os aspectos pragmáticos, funcionais, ergonômicos, culturais e simbólicos. Nesse sentido, investiga-se sobre o usuário proposto: idade, sexo, origem - história pessoal; profissão/ocupação; características pessoais, temperamento, valores; rotina, hábitos - o cotidiano: sono, alimentação e trabalho; lazer: hobbies, colecionismo, entretenimento; relações pessoais - família, amigos; usuários da moradia - funcionários e prestadores de serviço; equipamento mobiliário, acessórios e objetos de arte existentes; demandas; qualificação da ambiência.

Os dados de território e usuário são organizados em planilha onde registra-se as informações levantadas que geram análises sobre a relação do aspecto espacial e o usuário. Estas análises possibilitam ao aluno realizar reflexão avaliativa, confronto de informações e cruzamento de diferentes dados, somados ao repertório pessoal do profissional. Em seguida, a partir das análises realizadas, geram-se diagnoses, que podem determinar ações que irão balizar as possíveis soluções projetuais.

\section{O conceito}

Os resultados das análises dos dados levantados e as diagnoses realizadas, no método de Planejamento Espacial produzem um número elevado de informações que o aluno deve aprimorar e reorganizar através de resumos estendidos. É fundamental a análise atenta do aluno para destacar os aspectos que irão de fato contribuir com soluções projetuais adequadas e descartar informações que podem não ser necessárias para esta fase de planejamento espacial.

Objetiva-se nesta fase do trabalho formular um conceito que traduza a concepção formal do projeto. Nesse sentido, entende-se conceito como uma "representação mental de um objeto abstrato ou concreto que se mostra como instrumento fundamental do pensamento em sua tarefa de identificar, descrever e classificar os diferentes elementos e aspectos da realidade." (HOUAISS, 2009).

Coelho (2011, p. 168) explica que "conceito se estabelece a partir da compreensão e extensão de um objeto, englobando seus atributos, qualidades e elementos constitutivos." Nesse sentido, entende-se que a correta compreensão e elaboração das análises e diagnoses, realizados no método de Planejamento Espacial sobre determinados dados, poderão contribuir significativamente com o enriquecimento do conceito proposto pelo aluno.

Gibbs (2014) apresenta uma visão mais mercadológica e pragmática no processo de elaboração do conceito e explica que "alguns profissionais baseiam o processo criativo em um fato concreto e 


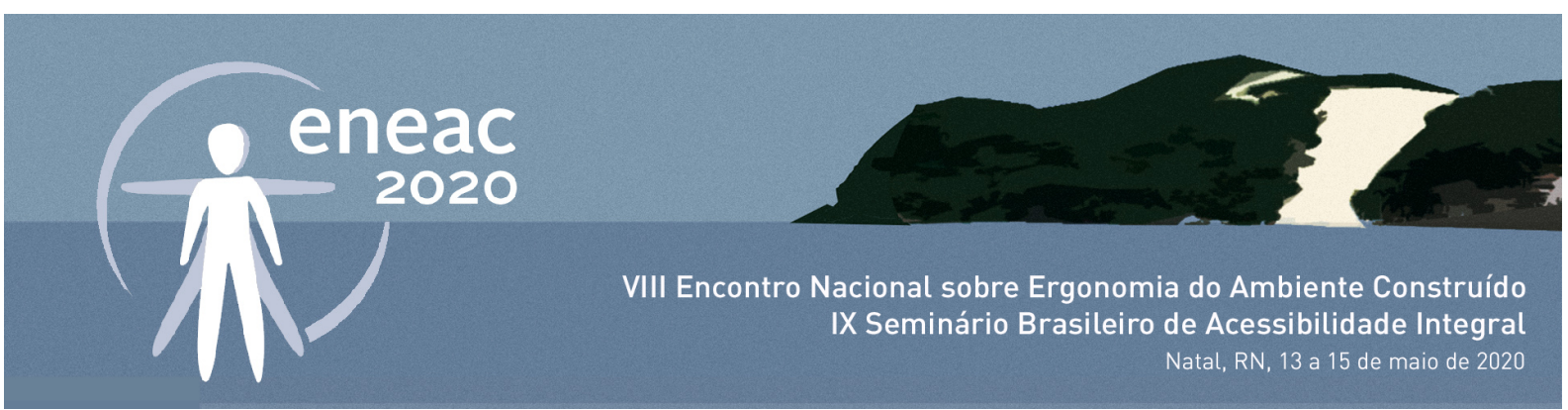

trabalham principalmente com a análise do projeto." Desta forma cita o exemplo que o designer pode solicitar ao cliente três palavras que transmitam as características desejadas, como leveza, elegância e conforto. Como alternativa, lembra que "outros profissionais podem buscar inspiração nos elementos naturais próprios do local onde o imóvel se localiza". (GIBBS 2014, p. 62)

Por fim, Gibbs (2014) chama atenção para "ao estabelecer o conceito de projeto, o designer deve levar em consideração as limitações de fatores como o orçamento, o próprio imóvel e o estilo de vida do cliente." Tais considerações demonstram a visão pragmática e comercial da autora, que apesar de significativos, no entender dos autores deste artigo, corre-se o risco de resvalar em conceitos repetitivos e que talvez, traduzam menos a identidade do usuário na concepção formal do projeto.

\section{ERGONOMIA DO AMBIENTE CONSTRUÍDO - EAC}

A Ergonomia do Ambiente Construído - EAC é um segmento da ergonomia que amplia seu olhar para além do usuário, da tarefa e dos objetos, levando em consideração o ambiente ${ }^{6}$. Considerando-se a áurea "juvenil" da ergonomia como disciplina científica - que completa 71 anos em 2020, quando comparada a outras áreas do conhecimento, torna-se necessário sempre resgatar e reafirmar algumas definições e conceitos de sua aplicação no ambiente construído.

Mont'Alvão e Villarouco (2011) explicam que existe uma evidente necessidade dos conhecimentos da ergonomia nos projetos de design (projetos de interiores) e arquitetura que contemplam o ambiente construído, considerando-se a integração existente:

[...] o ambiente arquitetônico com o ambiente do desenvolvimento das tarefas, de acordo com as capacidades, habilidades e limitações humanas - o que inclui características como percepção, compreensão e interação com o espaço - parece clara a necessidade dos conhecimentos da Ergonomia nos projetos de Design e a Arquitetura que contemplam o ambiente construído. (MONT'ALVÃO; VILLAROUCO, 2011, p:14)

Ribeiro e Mont'Alvão (2004) defendem que a Ergonomia do Ambiente Construído "visa uma abordagem mais completa para o estudo da melhor adaptação do ambiente construído às habilidades e limitações humanas". Os estudos de EAC abordam os principais elementos que são de grande importância para a relação humano/ambiente e as características humanas no desenvolvimento de suas atividades e as tarefas realizadas. (RIBEIRO; MONT'ALVÃO In: MORAES, 2004, p. 87)

As ponderações de Bins Ely (2003) são lembradas por Villarouco e Andreto (2008) que explica "toda atividade humana exige um determinado ambiente físico para sua realização. Portanto, se considerarmos tanto a diversidade de atividades quanto a diversidade humana - diferenças de habilidades por exemplo, podemos entender que as características do ambiente podem dificultar ou facilitar a realização das

\footnotetext{
6 A palavra ambiente é empregada neste texto considerando seu significado mais amplo, assemelhando-se à ambiência, em Arq., conforme dicionário Houaiss: "espaço preparado para criar um meio físico e estético (ou psicológico) próprio para o exercício de atividades humanas; ambiente."

7 A Profa Anamaria de Moraes cita Karwowski (IEA, 1996), reforçando o caráter de disciplina científica desse conhecimento: "a Ergonomia, também conhecida como Human Factors (fatores humanos - Estados Unidos, Canadá, México e Inglaterra), é uma disciplina científica que trata da interação entre os homens e a tecnologia. A Ergonomia integra o conhecimento proveniente das ciências humanas para adaptar tarefas, sistemas, produtos e ambientes às habilidades e limitações físicas e mentais das pessoas."
} 


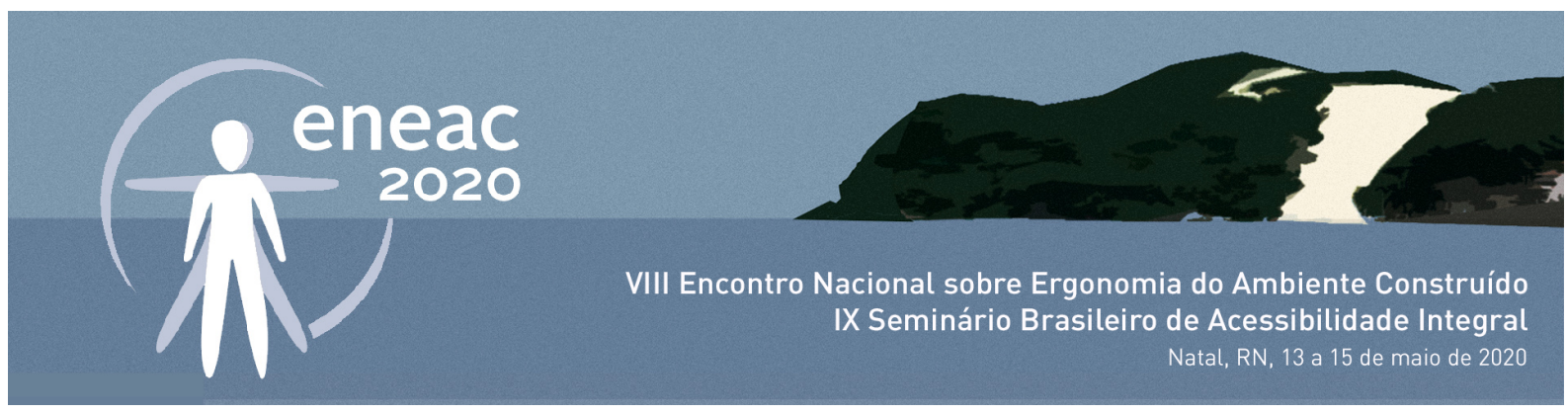

atividades. Quanto um ambiente físico responde às necessidades dos usuários tanto em termos funcionais (físicos/cognitivos) quanto formais (psicológicos), certamente terá um impacto positivo na realização das atividades." (VILLAROUCO; ANDRETO, 2008 apud BINS ELY, 2003, p. 524)

Tudo isso demonstra que os estudos acerca do desempenho do ambiente pertencem a um campo amplo que vai muito além dos aspectos simplesmente arquitetônicos. Sob esse entendimento as questões que envolvem o trinômio ambiente construído, comportamento humano e desempenho de tarefa, têm encontrado abrigo nos conceitos da EAC, cujos postulados se fundamentam na Psicologia Ambiental e na Ergonomia.

Villarouco e Mont'Alvão (2011) vão mais além, quando observam a necessidade de exceder os aspectos puramente físicos. São assertivas em defender que "a ergonomia do ambiente extrapola as questões puramente físicas, focando seu posicionamento na adaptabilidade e conformidade do espaço às tarefas e atividades que neles se irão desenvolver, mas também mediados pelo sentimento e percepção do usuário." Desta forma concluem que, a EAC busca elucidar suas questões amparada nos conhecimentos "da antropometria, da percepção ambiental e da ergonomia cognitiva, conceitos do conforto térmico, acústico e lumínico e da acessibilidade integral, além de metodologias auxiliares na composição de arranjos produtivos" (VILLAROUCO; MONT'ALVÃO, 2011 p. 30)

Pode-se afirmar, conforme as definições apresentadas, que a EAC busca a interação do usuário com o ambiente, o mobiliário, os objetos e a tarefa dentro de um mesmo sistema. Seria um equívoco tentar estudar um ou dois desses elementos de forma isolada sem considerar as influências e as consequências dos demais ${ }^{8}$. Atento às assertivas apresentadas, destaca-se na sequência os princípios básicos da EAC e de que forma estes princípios são tratados no ensino do método de Planejamento Espacial, no curso de <OMITIDO REVISÃO CEGA>.

\section{Princípios básicos da Ergonomia do Ambiente Construído}

Moraes (2004) também defendia o pensamento de que a Ergonomia do Ambiente Construído (ou Ergonomia Ambiental, como ela tratava) não se restringia apenas aos naturais problemas físicoambientais, como iluminação, temperatura, radiação, ruído, vibração e cor - e desta forma acreditava que o tema não deveria ser tratado como "microergonomia", junto com a estação de trabalho. A autora corroborava com os objetivos gerais do The Environmental Design Technical Group (Grupo técnico Design do Ambiente Construído), pertencente ao Human Factors and Ergonomics Society HFES $^{9}$ (Fatores Humanos e Sociedade da Ergonomia), que tem como um dos objetivos gerais promover e incentivar a integração dos princípios ergonômicos ao design de ambientes. Este grupo técnico da HFES considera "as relações entre o comportamento humano e o ambiental projetado (construído, habitado), observando áreas comuns de pesquisa e interesses, que incluem aspectos ergonômicos e macroergonômicos do design dentro do lar, escritórios e estabelecimentos industriais". Desta forma a autora compreende (e defende) que "ao termo ambiental cabem aspectos que contemplam desde

8 Algumas metodologias que buscam elucidar tais questões foram tratadas no artigo publicado: OLIVEIRA, Gilberto; RANGEL, Márcia; MONT'ALVÃO, Cláudia. UMA VISÃO CRÍTICA SOBRE AS METODOLOGIAS UTILIZADAS NAS PESQUISAS DE ERGONOMIA DO AMBIENTE CONSTRUÍDO - A CONSTELAÇÃO DE ATRIBUTOS. Revista ErgodesignHCI, [S.I.], v. 1, n. 2, p. $10-$ 17, dec. 1969. ISSN 2317-8876. Disponível em: <http://periodicos.puc-rio.br/index.php/revistaergodesignhci/article/view/36>. Acesso em: 18 jan. 2020. doi: http://dx.doi.org/10.22570/ergodesignhci.v1i2.36.

9 HFES - Human Factors Ergonomics Society < http://tg.hfes.org/edtg/> Acesso em: 18. jan. 2020 


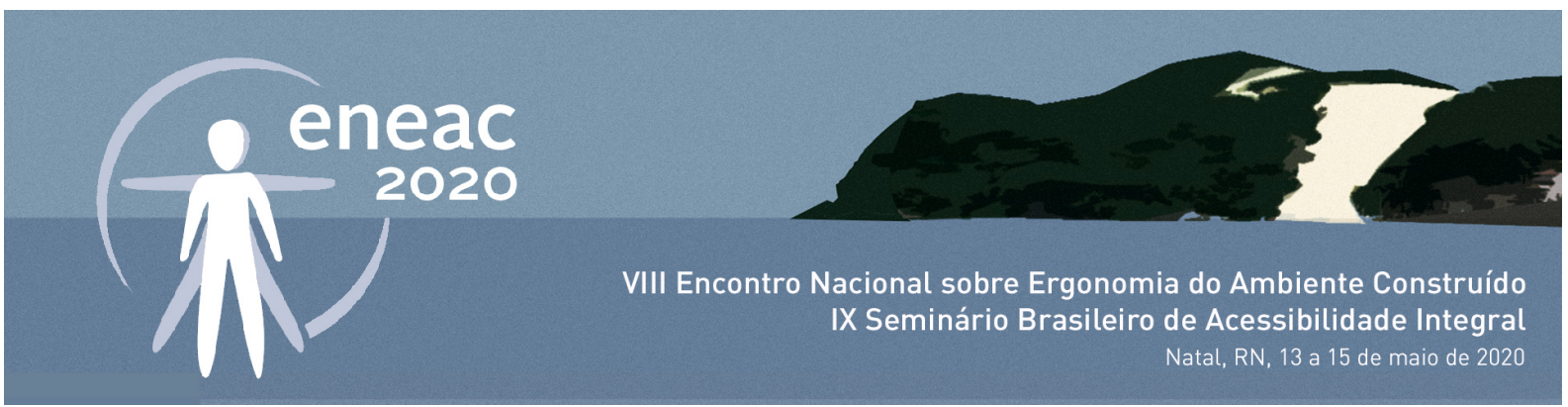

questões amplas, como a ecologia, até aspectos mais restritos, como iluminação e temperatura de um ambiente." (MORAES 2004, p. 8)

Bins Ely (2004) expõe a importância de se conceber espaços que "atendam tanto às necessidades funcionais quanto às necessidades formais ou estéticas dos usuários." Nesse sentido a autora aponta que:

\begin{abstract}
[...] as necessidades funcionais dos usuários estão diretamente relacionadas com as exigências da tarefa, e para atender a essas demandas, os profissionais realizadores do projeto devem prioritariamente considerar: dimensão e forma do espaço, dos equipamentos e mobiliários; fluxos de circulação e disposição do mobiliário (layout); conforto térmico, lumínico e acústico." As necessidades formais ou estéticas dos usuários, por sua vez, estão diretamente ligadas às sensações provocadas pelo ambiente, relacionadas com as preferências ou os valores dos indivíduos, dependendo de sua história pessoal, de seu contexto sociocultural. (COSTA; SIQUEIRA, 2015 apud BINS ELY, 2004 p. 38)
\end{abstract}

Corroborando com o pensamento de Bins Ely (2004) sobre os desafios de projetar ambientes físicos que atendam as necessidades dos usuários, de forma eficaz e os ensinamentos de Moraes (2005 e 2012), Moraes e Mont'Alvão (2009) e ainda as considerações de Mont'Alvão e Villarouco (2011), todos já citados aqui, aponta-se os cinco princípios que servem de base a ser considerado quando se trata de EAC e como cada princípio é tratado na aplicação do método de Planejamento Espacial do curso de Composição de Interior - EBA - UFJR. Para melhor compreensão os enunciados estão organizados na Tabela 1, a seguir. Ao final apresenta-se o resultado da análise realizada.

\title{
Tabela 1
}

\section{Princípios da Ergonomia do Ambiente Construído e o Método de Planejamento Espacial}

1. Considerar a interação do homem com o ambiente

Considerar as características e limitações culturais, cognitivas, emocionais e físicas do usuário. Sabe-se que o homem é um produto do meio que habita. Deve-se pensar as interações entre os espaços, partindo-se de um plano geral do ambiente, em seguida o estudo dos ambientes urbanos, de ambientes públicos abertos (como praças e entornos) e públicos fechados (como aeroportos e hospitais), chegando-se ao estudo mais específico dos ambientes laborais e dos ambientes domésticos.
Método de Planejamento Espacial

Os ambientes funcionam de forma sistêmica e inter-relacionam-se entre si. Quando desenvolvemos um projeto de interiores em um determinado bairro, há de se considerar as interferências da rua, do entorno imediato, do bairro, da cidade etc. As interferências (positivas ou negativas) são consideradas na interação com o usuário. No método de Planejamento Espacial, essas interrelações são realizadas através de análises e diagnoses sobre os dados levantados.

\section{Considerar o princípio de usabilidade} Método de Planejamento Espacial

Moraes (2004) chama atenção para o fato de que esse termo não se relaciona apenas com o ergodesign de interfaces computadorizadas, mas igualmente ao ergodesign de produtos, informacional e do ambiente
O princípio de usabilidade no método de Planejamento Espacial é considerado no desenvolvimento das soluções de projeto, através de 


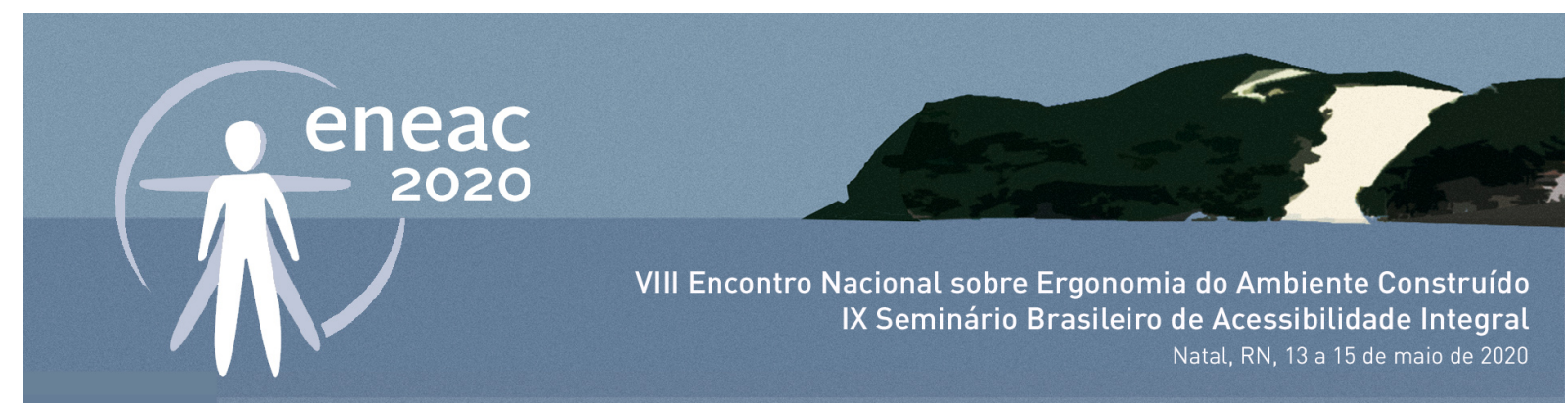

construído e habitado. A ISO 9241-11 - International

Standarts Association define usabilidade como "a efetividade, eficiência e satisfação com as quais usuários específicos atingem metas específicas em ambientes particulares".${ }^{10} \mathrm{~A}$ efetividade se refere ao quanto uma meta ou tarefa é alcançada. No caso da EAC, tem-se a capacidade de se movimentar de um ponto a outro do espaço e desempenhar suas tarefas, por exemplo. A eficiência se refere à quantidade de esforço que o indivíduo investe para atingir a sua meta. No que se refere à eficiência no âmbito da EAC, mantendo o mesmo exemplo, além de ir de um ponto a outro do espaço, considera-se a economia de tempo e a segurança, ou seja, melhora a qualidade do trabalho. A satisfação se refere ao nível de conforto e de aceitabilidade dos usuários ao usar um produto. É um aspecto bem mais subjetivo, pois depende da opinião e experiência de cada usuário, e é também o mais difícil de ser mensurado. Nos estudos de EAC pode-se ter satisfação com a paisagem, com a tranquilidade do ambiente, com a estética do ambiente construído, etc. Constata-se que a usabilidade do ambiente construído e habitado - seja meio urbano, o espaço público ou laboral - deve facilitar as atividades dos usuários, seja na sua utilização cotidiana, no trabalho ou no lazer. (MORAES, 2004, p. 11,12)

\section{Considerar a abordagem sistêmica}

A noção do sistema homem-máquina sempre se destacou como um dos conceitos básicos da Ergonomia, ao focalizar a inter-relação do homem (ser humano) com utensílios, equipamentos, máquinas e ambientes. "O sistema possui tanto um ambiente interno quanto externo." Naturalmente que um sistema "não pode ser conceituado sem a definição do seu ambiente, pois este diferencia as coisas que são do sistema daquelas que não são. A definição daquilo que constitui um ambiente para um sistema em particular depende de que objetos devem ou não ser considerados como parte do sistema." (MORAES e MONT'ALVÃO, 2009, p. 43)

Estabelece-se a necessidade de uma abordagem sistêmica quando se trata de avaliar o ambiente sob a ótica da ergonomia. "Uma completa avaliação ergonômica do ambiente abrange um vasto leque de variáveis, demandando esforços a partir de diversas áreas envolvidas no processo de formação do espaço edificado."

(VILLAROUCO; MONT'ALVÃO, 2011 p. 30) análises de esboços e desenhos em escala, relacionando-se com os dados levantados e analisados na primeira etapa do método empregado pelos alunos. Há de se considerar que para uma análise e aferimento do grau de efetividade, eficiência e satisfação de forma concreta, depende-se da realização material do projeto com uso de metodologias adequadas. - o que por razões obvias não ocorre na aplicação do método de Planejamento Espacial.
Método de Planejamento Espacial

Os ambientes funcionam de forma sistêmica e inter-relacionam-se entre si, considerando o usuário o foco central do "problema de projeto" a ser resolvido. Quando desenvolvemos um projeto de interiores em determinado bairro, há de se considerar as interferências da rua, do entorno imediato, do bairro, da cidade etc e todas as interações com o usuário. No método de Planejamento Espacial, essas inter-relações são realizadas através de análises e diagnoses sobre os dados levantados.

10 A Norma ABNT NBR ISO 9241-11 define usabilidade e explica como identificar a informação necessária a ser considerada na especificação ou avaliação de usabilidade de um dispositivo de interação visual em termos de medida de desempenho de satisfação do usuário. Fonte: <http://www.abntcatalogo.com.br/norma.aspx?ID=86090>. Acesso em: 05. jan. 2020 


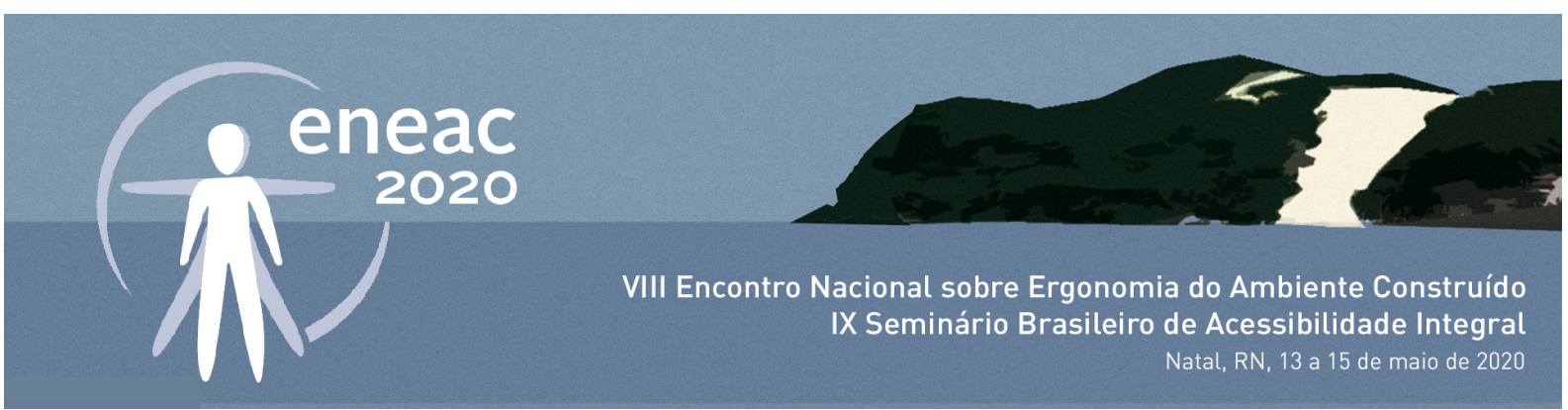

\begin{tabular}{|c|c|}
\hline 4. Enfoque centrado no usuário & Método de Planejamento Espacial \\
\hline $\begin{array}{l}\text { A visão centrada no usuário concentra-se no indivíduo como } \\
\text { o único controlador do sistema. Moraes \& Mont'Alvão } \\
\text { (2009) explica que "a ênfase da Ergonomia moderna tem } \\
\text { sido investigar o operador e o ambiente como parceiros } \\
\text { dentro do sistema de trabalho como uma totalidade, mais } \\
\text { do que examinar em mínimos detalhes os componentes que } \\
\text { constituem qualquer loop homem-máquina". O acesso ao } \\
\text { ambiente deve respeitar as características físicas, culturais, } \\
\text { psicossociais e cognitivas do usuário, incluindo-se aspectos } \\
\text { de acessibilidade física e orientabilidade. Deve ser global, } \\
\text { universal em todos os sentidos e para todas as pessoas, } \\
\text { focando seu posicionamento na adaptabilidade e } \\
\text { conformidade do espaço às tarefas e atividades que nele } \\
\text { irão se desenvolver. (Ibid. p. 45) }\end{array}$ & $\begin{array}{l}\text { O enfoque no usuário é parte essencial } \\
\text { do método de Planejamento Espacial. } \\
\text { As interações do usuário com o } \\
\text { território, considerando suas } \\
\text { características (físicas e pessoais) e os } \\
\text { aspectos culturais, cognitivas, } \\
\text { emocionais, etc. servem de demanda } \\
\text { para elaborar a proposta de projeto de } \\
\text { interiores. Exige-se no final do processo } \\
\text { que o aluno, ao propor seu projeto, } \\
\text { consiga estabelecer links que } \\
\text { identifique o usuário através da ideia } \\
\text { apresentada, além das soluções } \\
\text { técnicas pertinentes a todo projeto. }\end{array}$ \\
\hline 5. Garantir conforto ambiental & Método de Planejamento Espacial \\
\hline $\begin{array}{l}\text { Garantir o conforto adequado dos aspectos: acústico, } \\
\text { luminosidade e hidrotérmico, radiação, ruído, vibração e cor, } \\
\text { além de adequação de materiais (revestimentos e } \\
\text { acabamentos) possibilitando ao usuário realizar escolhas e } \\
\text { controlar as condições ambientais que mais Ihe agradam. } \\
\text { Adequação de layout, fluxos e dimensionamento. Garantir que } \\
\text { as necessidades subjetivas dos usuários sejam atendidas, como } \\
\text { as sensações provocadas pelo ambiente relacionadas com as } \\
\text { preferências pessoais, valores e aspectos culturais, entre } \\
\text { outros. }\end{array}$ & $\begin{array}{l}\text { A garantia do conforto térmico, } \\
\text { acústico, lumínico e a escolha de } \\
\text { materiais adequados a proposta de } \\
\text { projeto, além das soluções adequadas } \\
\text { de layout, fluxo e escolha acertada de } \\
\text { mobiliário, acessórios e objetos, são } \\
\text { os desafios que devem ser cumpridos } \\
\text { na etapa final do método de } \\
\text { Planejamento Espacial. Através de } \\
\text { representação gráfica elaborada em } \\
\text { escala, constituído de planta baixa } \\
\text { falada, cortes, vistas, perspectivas e } \\
\text { caderno de materiais o projeto de } \\
\text { interiores do aluno é avaliado } \\
\text { considerando-se: como resolveu os } \\
\text { problemas projetuais propostos, } \\
\text { soluções encontradas e ainda, sua } \\
\text { análise sobre o processo } \\
\text { implementado. }\end{array}$ \\
\hline
\end{tabular}

Após análise criteriosa, verifica-se que há cuidadosa abordagem na aplicação do método de Planejamento Espacial em contemplar todos os princípios da EAC durante o processo de aplicação, execução e orientação acadêmica. Aponta-se que há maior ênfase em considerar: o homem e o ambiente; a abordagem sistêmica; enfoque centrado no usuário; conforto ambiental. Menor ênfase apenas ao princípio de usabilidade, por razões já mencionadas. 


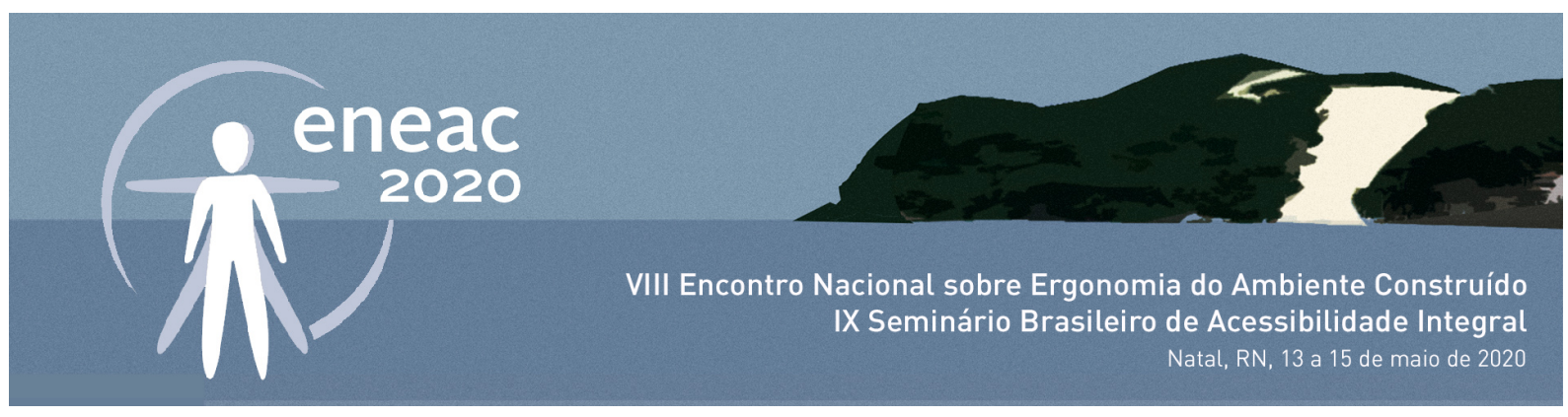

\section{CONSIDERAÇÕES FINAIS}

O método de Planejamento Espacial é uma estratégia que visa abarcar os inúmeros problemas de projeto. Considerando que sua aplicação tem sido em um ambiente controlado, como é o ambiente acadêmico, faz-se necessário tecer algumas considerações sobre a aplicação da metodologia nos quais busca-se o aperfeiçoamento constante. Trata-se de uma ferramenta metodológica que, devido seu formato proposto, os dados e as análises são construídos entre todos os alunos que participam da disciplina e o professor, considerando especialmente um território e um usuário específicos, utilizados como estudo de caso a cada semestre letivo. Face a exposição realizada, traça-se algumas considerações sobre o uso dessa ferramenta didática pedagógica:

- O aspecto quantitativo e qualitativo dos dados levantados, depende do empenho dos alunos e da orientação efetiva do professor da disciplina;

- As análises e diagnoses precisam ser exaustivamente estimuladas junto aos discentes, considerando que a pouca experiência em análises de dados e reflexões, constituem-se como um problema de formação acadêmica endêmico;

- O processo de análise e diagnose a partir dos dados levantados, referentes ao problema de projeto, estimulam os alunos à reflexão sobre o processo de construção projetual como um todo, o que contribui para o aprendizado significativamente;

- A dinâmica de aplicação e elaboração da planilha do método de Planejamento Espacial, realizado de forma colaborativa em grupo, favorece a participação dos discentes que se sentem estimulados a contribuir para a construção do trabalho e troca de ideias;

- Considerando o número de itens o trabalho muita das vezes torna-se exaustivo;

- A qualidade dos dados e as análises adequadas irão gerar diagnoses úteis para etapas seguintes do projeto;

- A deficiência no levantamento dos dados, bem como análises mal estruturadas, irá gerar diagnoses deficientes, o que pode comprometer as etapas seguintes do projeto;

- A experiência do docente na aplicação do método de Planejamento Espacial, é um atributo a ser considerado de forma positiva;

- Os conceitos elaborados a partir da planilha elaborada no método de Planejamento Espacial, tem demonstrado importante subsídio como ferramenta para criação de conceitos criativos, que favorecem as etapas seguintes do projeto;

- Vale destacar que a última etapa do processo, relativo à representação gráfica do projeto elaborada manualmente, com instrumentos de desenho, tem surtido resultados positivos no que se refere ao desenvolvimento de habilidades e reflexão crítica sobre o processo projetual;

- Por fim, ressalta-se que através da aplicação contínua do método, busca-se o constante aperfeiçoamento. Planeja-se realizar a análise da metodologia em outros cenários de uso coletivo, como projetos comerciais, institucionais, etc.

A ação projetual por si só é uma atividade complexa. O ensino de projeto requer uma atuação criativa, acúmulo de informação, conhecimento e alguma experiência. Constata-se neste artigo que os princípios da Ergonomia do Ambiente Construído têm sido considerados na aplicação do método de Planejamento Espacial, junto aos alunos de Composição de Interior I-EBA - UFRJ, especialmente os princípios 01,03,04 e 05 com mais ênfase. Entende-se que se faz necessário, sempre que possível, 


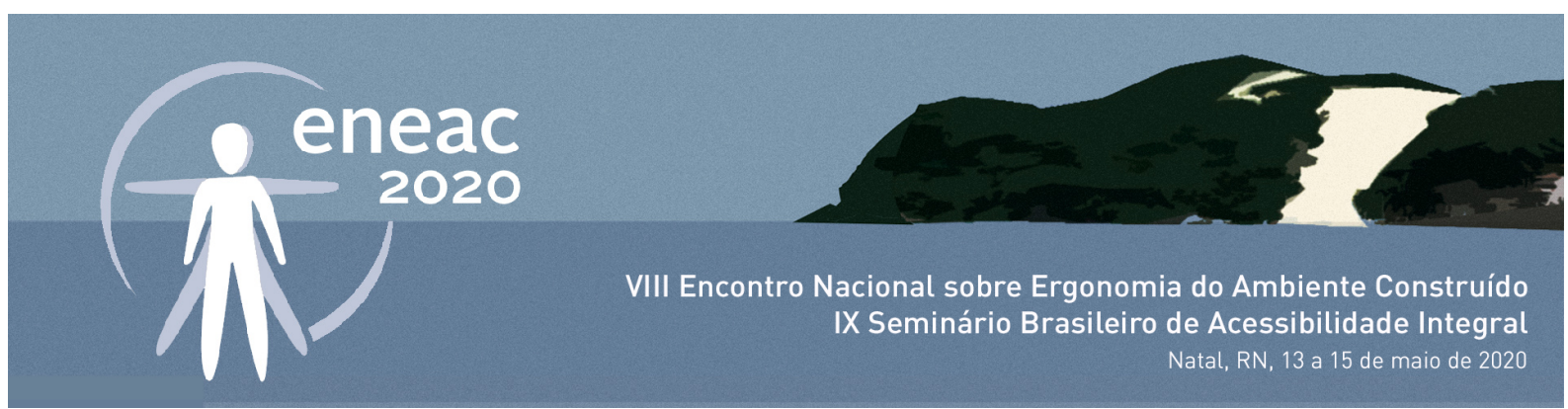

o registro das metodologias de projeto aplicadas nos centros de ensino, com um olhar crítico sobre o processo e as constantes buscas por melhorias.

\section{AGRADECIMENTOS}

À Universidade Federal do Rio de Janeiro - UFRJ, em especial à Escola de Belas Artes e o corpo docente e discente do curso Composição de Interiores, que tem contribuído para interessantes experiências acadêmicas.

\section{REFERÊNCIAS}

BINS Ely, Vera In: MORAES, A. de (org.) Ergodesign do ambiente construído e habitado. Rio de Janeiro: iUsEr, 2004

BROOKER, G. \& STONE, S. O que é design de interiores. Tradução: André Botelho. São Paulo: Senac, 2014. Título Original: What is interior design?

COELHO, L. A. (org.). Conceitos-chave em design. Rio de Janeiro: 2AB / Novas ideais, 2011

GIBBS, Jenny. Design de interiores: guia útil para estudantes e profissionais. Tradução Claudia Ardión. Barcelona: Gustavo Gili, 2014. Título original: Interior Design

HOUAISS, A. Dicionário Houaiss da língua portuguesa. Rio de Janeiro: Objetiva, 2009

KARLEN, Mark. Planejamento de espaços internos. Tradução: Alexandre Salvaterra. 3ed. Porto Alegre: Bookman, 2010. Título original: Space Planning Basics

LAWSON, B. Como arquitetos e designers pensam. Tradução: Maria Beatriz Medina. 2 ed. São Paulo: Oficina de textos, 2011. Título original: How designers think: the design process demystified.

COSTA, Lourival; SIQUEIRA, Cecília; AS NECESSIDADES DOS USUÁRIOS NOS ESPAÇOS RESIDENCIAIS, NA PERCEPÇÃO DE ARQUITETOS E DESIGNERS DE INTERIORES. Estudos em Design, v. 23, n. 3, 2015 p. 36 - 45. ISSN 1983-196X. Disponível em: < https://estudosemdesign.emnuvens.com.br/design/article/view/267. >. Acesso em: 20. jan. 2020.

MONT'ALVÃO, C.; VILLAROUCO, V. Um novo olhar para o projeto. Teresópolis-RJ: 2AB, 2011, p. 184

MORAES, A. de (org.) Ergodesign do ambiente construído e habitado. Rio de Janeiro: 2AB, 4a ed. 2004

MORAES, A. de. Usuário. In: COELHO, Luiz Antônio (org.). Conceitos-chave em design. Rio de Janeiro: 2AB/Novas ideias, 2011. p. 92-93.

MORAES, A. de.; MONT'ALVÃO, C. Ergonomia: conceitos e aplicações. 3a ed., Rio de Janeiro: 2AB, 2009, p. 43

PAZMINO, A. Como se cria. 40 métodos para design de produtos. São Paulo: Blucher, 2015

RIBEIRO, L.; MONT'ALVÃO, C. In: MORAES, A. de (org.) Ergodesign do ambiente construído e habitado. Rio de Janeiro: iUsEr, 2004

RISÉRIO, A. A casa no Brasil. Rio de Janeiro: Topbooks, 2019

SILVA, E. Uma introdução ao projeto arquitetônico. Porto Alegre: Editora UFRGS, 1998

VILLAROUCO, V.; ANDRETO, L. F. M. Avaliando desempenho de espaços de trabalho sob o enfoque da ergonomia do ambiente construído. Produção, v. 18, n. 3, p. 523-539, 2008, p. 524 